\title{
Research Article \\ Effect of Heat Treatment on Corrosion Behaviors of Mg-5Y-1.5Nd Alloys
}

\author{
Xiumin Ma, Quantong Jiang, Yantao Li, and BaoRong Hou \\ Marine Corrosion and Protection Centre, Institute of Oceanology, Chinese Academy of Sciences, \\ No. 7 Nanhai Road, Qingdao 266071, China \\ Correspondence should be addressed to Xiumin Ma; xma@qdio.ac.cn and Quantong Jiang; jqthappyfly@163.com
}

Received 16 November 2015; Revised 10 March 2016; Accepted 27 March 2016

Academic Editor: María Isabel Pividori

Copyright (C) 2016 Xiumin Ma et al. This is an open access article distributed under the Creative Commons Attribution License, which permits unrestricted use, distribution, and reproduction in any medium, provided the original work is properly cited.

Corrosion behavior of Mg-5Y-1.5Nd alloy was investigated after heat treatment. The microstructure and precipitation were studied by scanning electron microscope (SEM) and energy dispersive spectrometer (EDS). The weight loss rates of different samples were arranged as T6-24 $\mathrm{h}>\mathrm{T} 6-6 \mathrm{~h}>\mathrm{T} 6-14 \mathrm{~h}>$ as-cast $>\mathrm{T} 4$. The open circuit potential (OCP) showed that T4 sample had a more positive potential than that of other samples. The potentiodynamic polarization curves showed that the T6-24h sample had the highest corrosion current density of $245.362 \mu \mathrm{A} \cdot \mathrm{cm}^{-2}$, whereas the T4 sample had the lowest at $52.164 \mu \mathrm{A} \cdot \mathrm{cm}^{-2}$. The EIS results confirmed that the heat treatment reduced the corrosion resistance for $\mathrm{Mg}-5 \mathrm{Y}-1.5 \mathrm{Nd}$ alloy, because the precipitations acted as the cathode of electrochemical reactions to accelerate the corrosion process. The corrosion rates of different samples were mainly determined by the amount and distribution of the precipitations. The precipitations played dual roles that depended on the amount and distribution. The presence of the phase in the alloys could deteriorate the corrosion performance as it could act as an effective galvanic cathode. Otherwise, a fine and homogeneous phase appeared to be a better anticorrosion barrier.

\section{Introduction}

Mg-Y-Nd alloys have gained successful application because of their high strength and creep resistance [1]. Yttrium (Y) serves as an effective solid solution hardener; therefore, Ycontaining Mg alloys have good mechanical properties [2,3]. Neodymium $(\mathrm{Nd})$ can refine the grain size and improve creep resistance of $\mathrm{Mg}$ alloys $[4,5]$. Based on the $\mathrm{Mg}$-YNd system, many commercial alloys have been successfully developed, including WE43, WE54, and EW75 alloys [69]. Considerable effort has been dedicated to the corrosion properties of Mg-Y-Nd based alloys [10-12]. There are many different precipitated phases that may form in the Mg-Y$\mathrm{Nd}$ system, such as the $\mathrm{Mg}_{3} \mathrm{Nd}, \mathrm{Mg}_{12}(\mathrm{YNd})$, and $\mathrm{Mg}_{3}(\mathrm{YNd})$ phases [13]. Davenport et al. [14] demonstrated that the Yrich regions slowed the propagation of corrosion in WE43 alloy by a more homogenous distribution of Y. Corrosion resistance of $\mathrm{Mg}-\mathrm{Nd}-\mathrm{Zn}-\mathrm{Zr}$ alloy was mainly ascribed to the grain refinement and the fine dispersed $\mathrm{Mg}_{12} \mathrm{Nd}$ [15]. Williams et al. [4] studied the influence of $\mathrm{Nd}$ additions on the corrosion behaviors of $\mathrm{Mg}$ and found that cathodic activation of corroded regions was proposed to derive from Nd-rich intermetallic grains.

Heat treatment can cause precipitated phases changes and redistribution of alloying elements. It has been reported that the precipitated phases have an effect on the corrosion resistance of aluminum-containing $\mathrm{Mg}$ alloys. Song et al. [1619] found that a solution treatment decreases the amount of second-phase particles inside the grains and weakens strong pinning on dislocations. Wang et al. [20] studied the change in the microstructure of AZ91D alloy during T4 or T6 treatments. Lu et al. [21] analyzed the corrosion behaviors of Mg3Zn alloy (T4 and T6) via electrochemical measurements, which found that large MgZn particles formed mainly on grain boundary and fine MgZn particles precipitated on matrix for T6 treatment. Ben-Hamu et al. [22] studied the relationship between microstructure and corrosion behavior of peak-aged Mg-Y-Gd-Zr alloy. From the above, the effect of heat treatment on the corrosion resistance of $\mathrm{Mg}$-Al alloys has been widely reported, especially AZ91 Mg alloy. However, the effect of heat treatment on the corrosion properties of Mg-Y$\mathrm{Nd}$ alloy has still not been well understood. 
TABLE 1: Thermal process of the Mg-5Y-1.5Nd alloys in this study.

\begin{tabular}{lcc}
\hline Heat treatment & Homogenizing & Aging \\
\hline As-cast & - & - \\
T4 & $535^{\circ} \mathrm{C}, 20 \mathrm{~h}+$ water quenching & - \\
T6 (early-aged) & $535^{\circ} \mathrm{C}, 20 \mathrm{~h}+$ water quenching & $225^{\circ} \mathrm{C}, 6 \mathrm{~h}+$ water quenching \\
T6 (peak-aged) & $535^{\circ} \mathrm{C}, 20 \mathrm{~h}+$ water quenching & $225^{\circ} \mathrm{C}, 14 \mathrm{~h}+$ water quenching \\
T6 (overaged) & $535^{\circ} \mathrm{C}, 20 \mathrm{~h}+$ water quenching & $225^{\circ} \mathrm{C}, 24 \mathrm{~h}+$ water quenching \\
\hline
\end{tabular}

In this work, Mg-5Y-1.5Nd alloys after heat treatment were investigated to reveal the influence of precipitations on the corrosion resistance during heat treatment. The relationship between microstructure and corrosion behavior of different samples was analyzed. The results showed that heat treatment significantly affected microgalvanic corrosion between cathodic phases and anodic $\alpha-\mathrm{Mg}$ matrix. The precipitations played dual roles that depended on the amount and distribution. The conclusion indicates that the corrosion properties of Mg-Y-Nd alloys can be modified by controlling the heat treatment process.

\section{Experiments}

2.1. Materials. The Mg-5Y-1.5Nd alloys were prepared by melting in an electrical resistance furnace in a steel crucible under protected gas consisting of $\mathrm{Ar}$ and $\mathrm{C}_{2} \mathrm{H}_{2} \mathrm{~F}_{4}$ in order to prevent burning of the melts. The materials were prepared from blending the appropriate proportions from ingots of commercial purity $\mathrm{Mg}$ (>99.95\%), Y (99.9\%), and $\mathrm{Nd}(99.9 \%)$. The highest smelting temperature was $850^{\circ} \mathrm{C}$ and the cast temperature was between $720^{\circ} \mathrm{C}$ and $750^{\circ} \mathrm{C}$.

The samples were cut from the ingot by electric spark linear cutting machine. Actual compositions of the alloy were detected by inductively coupled plasma-atomic emission spectrometry (ICP-AES). The chemical compositions were as follows: Y, 5.02; Nd, 1.50; Al, 0.019; Fe, 0.013; balance $\mathrm{Mg}$. The solution treatment (T4) was performed at $535^{\circ} \mathrm{C}$ for $12 \mathrm{~h}$ in argon atmosphere followed by water quench at $25^{\circ} \mathrm{C}$. The aging alloy was $\mathrm{T} 6$ heat treatment at $225^{\circ} \mathrm{C}$ for $6 \mathrm{~h}, 14 \mathrm{~h}$, and $24 \mathrm{~h}$. The detailed thermal process of the samples in this study was shown in Table 1.

2.2. Experimental Procedures. For gas collection, cubes of $1 \times 1 \times 1 \mathrm{~cm}$ were prepared and weighed and then sealed by epoxy with $1 \mathrm{~cm}^{2}$ exposed surface. A funnel was inverted on the sample to transfer the generated hydrogen bubbles into a buret during the course of immersion. The samples were polished with up to 5000-grit SiC paper and then measured using three replicate samples for each alloy in $3.5 \% \mathrm{NaCl}$ solution for $24 \mathrm{~h}$.

The samples for electrochemical tests were cubes of $1 \times$ $1 \times 1 \mathrm{~cm}$. Before the tests, the electrodes were encapsulated in epoxy resin with a surface of $1 \mathrm{~cm}^{2}$ exposed to $450 \mathrm{~mL} 3.5 \%$ sodium chloride solution (made with AR sodium chloride and deionized water) in a beaker at $25 \pm 1^{\circ} \mathrm{C}$. The OCP, potentiodynamic polarization curve, and EIS were obtained from a Solatron 2273 system. The potentiodynamic scanning was performed at $0.5 \mathrm{mV} / \mathrm{s}$ after the cell was held at the OCP for $400 \mathrm{~s}$. The EIS was measured with the frequency ranging from $10,000 \mathrm{~Hz}$ to $0.1 \mathrm{~Hz}$ with $5 \mathrm{mV}$ of amplitude of sinusoidal potential signals with respect to the OCP.

2.3. Analysis and Characterization Methods. The microstructures of Mg-5Y-1.5Nd alloys were characterized by SEM. EDS analysis was conducted on the alloys to confirm the phase identification. When the immersion test was completed, the corrosion products on the surface of different samples were removed in boiling chromic acid $\left(20 \% \mathrm{CrO}_{3}+1 \% \mathrm{AgNO}_{3}\right)$ for $5 \mathrm{~min} \mathrm{[23].} \mathrm{The} \mathrm{samples} \mathrm{were} \mathrm{then} \mathrm{quickly} \mathrm{washed} \mathrm{with}$ deionized water, dried, and weighed to obtain their final weight $\left(W_{1}\right)$. The difference between $W_{0}$ and $W_{1}$ is the corrosion weight loss $(\Delta w)$. The surface morphologies of samples without corrosion products were observed by SEM.

\section{Results and Discussion}

3.1. The Microstructure of Samples. The SEM photographs of $\mathrm{Mg}-5 \mathrm{Y}-1.5 \mathrm{Nd}$ alloy in different conditions were illustrated in Figure 1. As shown in Figure 1(a), the microstructure of as-cast alloy consisted of $\alpha-\mathrm{Mg}$ matrix, particle phases, and skeleton eutectic phases. The close-up view clearly showed that a small quantity of skeleton eutectic phases was distributed on the surface of as-cast alloy, whereas amounts of particle phases were mainly distributed discretely (Figure 1(b)). The microstructure of Mg-5Y-1.5Nd alloy had changed during homogenization annealing (T4). The volume fraction of the precipitations decreased, and the skeleton eutectic phases were almost invisible. The precipitations were almost dissolved completely except for less particle phases, and the supersaturated $\alpha-\mathrm{Mg}$ matrix was produced in Figure 1(c).

After T6-6 h heat treatment, amounts of particle phases precipitated along the grain boundary and within grains of the supersaturated $\alpha-\mathrm{Mg}$ phase. Meanwhile, a small quantity of skeleton eutectic phases began to form. T6 treatment made $\mathrm{Y}$ and $\mathrm{Nd}$ atoms diffuse towards grain boundaries to form precipitations, and this process reduced $\mathrm{Y}$ and $\mathrm{Nd}$ atoms concentration in the $\alpha$-Mg matrix. With a prolonged aging time, $\mathrm{Y}$ and $\mathrm{Nd}$-content in the $\alpha-\mathrm{Mg}$ matrix precipitated gradually and distributed uniformly (Figures $1(\mathrm{~d})-1(\mathrm{f})$ ). The precipitations would act as the cathode of electrochemical reaction to accelerate the corrosion process [24-26]. With a prolonged aging time, the amounts of skeleton eutectic precipitates increased and formed a continuous uniform distribution.

The EDS analyses were performed to characterize the components of as-cast Mg-5Y-1.5Nd alloy by more than three 


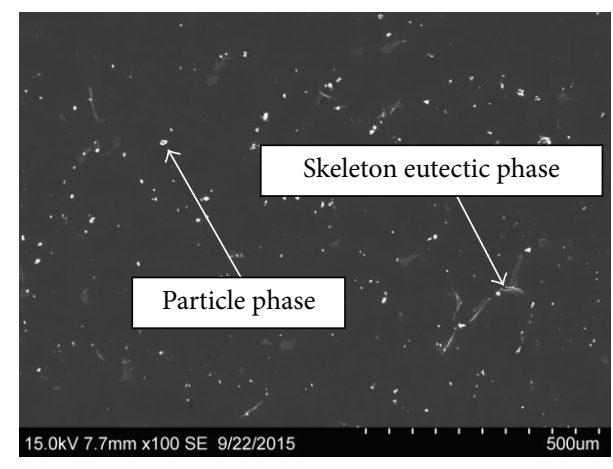

(a)

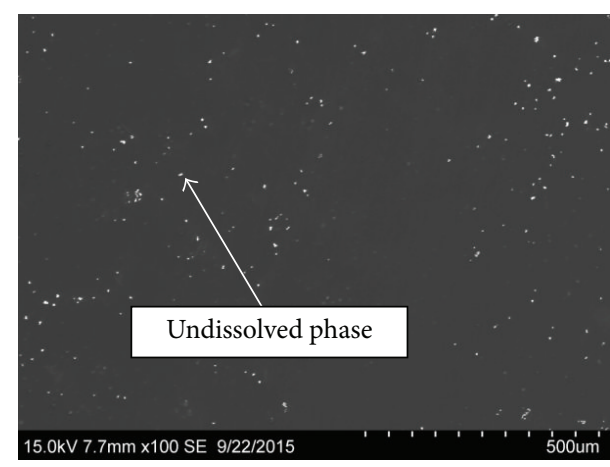

(c)

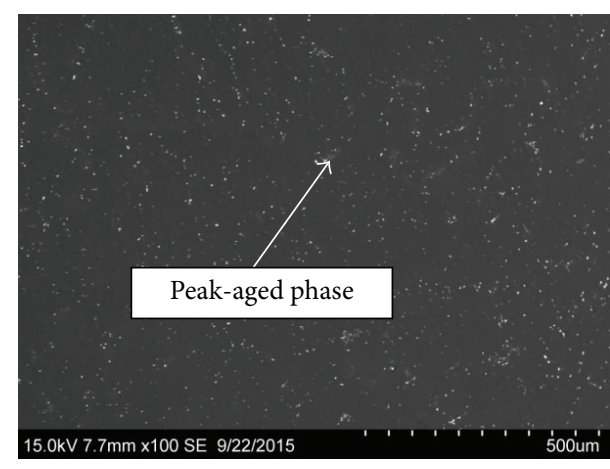

(e)

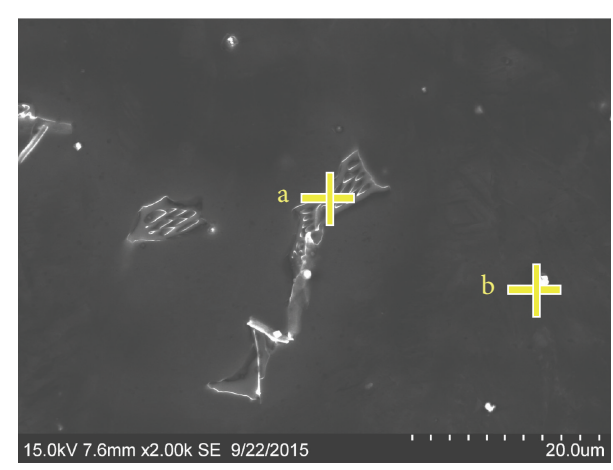

(b)

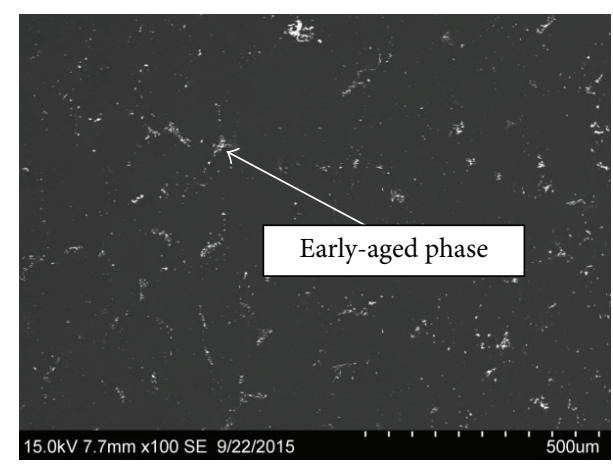

(d)

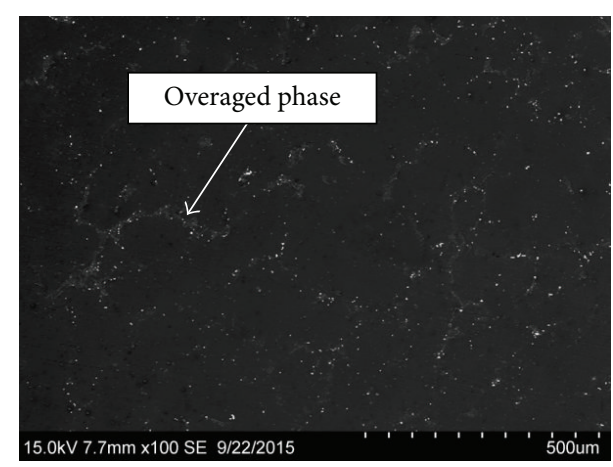

(f)

Figure 1: The SEM photographs of Mg-5Y-1.5Nd alloys: (a) as-cast, (b) close-up view of (a), (c) T4, (d) T6-6 h, (e) T6-14 h, and (f) T6-24 h.

replicate spots. The result was basically identical in Figure 2. The white contrast particle phases and the eutectic phases were arranged to be $\mathrm{Mg}_{3}(\mathrm{Y}, \mathrm{Nd})$ and $\mathrm{Mg}_{12}$ (Y,Nd), respectively. The great difference was that the content of $\mathrm{Y}$ in $\mathrm{Mg}_{3}(\mathrm{Y}, \mathrm{Nd})$ phase was higher than that in $\mathrm{Mg}_{12}(\mathrm{Y}, \mathrm{Nd})$ phase, but the $\mathrm{Nd}$ content was just the reverse. The contents of $\mathrm{Y}$ and $\mathrm{Nd}$ in the locations were rich due to the solute atoms enrichment in the solid/liquid interface during nonequilibrium solidification, whereas the solute atoms must be pushed into the grain boundary $[27,28]$.

3.2. Gas Collection and Weight Loss Rates. Gas collection was equivalent to employing a weight loss method for corrosion rate testing and was more convenient for calculating the average corrosion rate over a given period. In the current work, the corrosion rate was investigated by both hydrogen evolution and weight loss tests measured simultaneously for each sample. Figure 3 showed the average hydrogen evolution rates of different samples in $3.5 \% \mathrm{NaCl}$ for $24 \mathrm{~h}$. The corrosion rates of different samples increased with the prolonging of immersion time. The T6-24h sample showed the largest corrosion rate due to the amount and distribution of the precipitated phases, which acted as microcathodes for the microcells. During the period of immersion, the relative corrosion rates of the different samples can be ranked as T6$24 \mathrm{~h}>\mathrm{T} 6-6 \mathrm{~h}>\mathrm{T} 6-14 \mathrm{~h}>$ as-cast $>\mathrm{T} 4$.

The corrosion rate was calculated as follows: $C=\left(W_{0}-\right.$ $\left.W_{1}\right) / S$, where $C$ is the weight loss rates $\left(\mathrm{mg} \cdot \mathrm{cm}^{-2}\right), W_{0}$ is the original weight $(\mathrm{mg}), W_{1}$ is the final weight without corrosion products $(\mathrm{mg})$, and $S$ is the surface area $\left(\mathrm{cm}^{2}\right)$. Each type had three samples, so the corrosion rates were the average. Figure 4 shows that the T6-24h sample had 


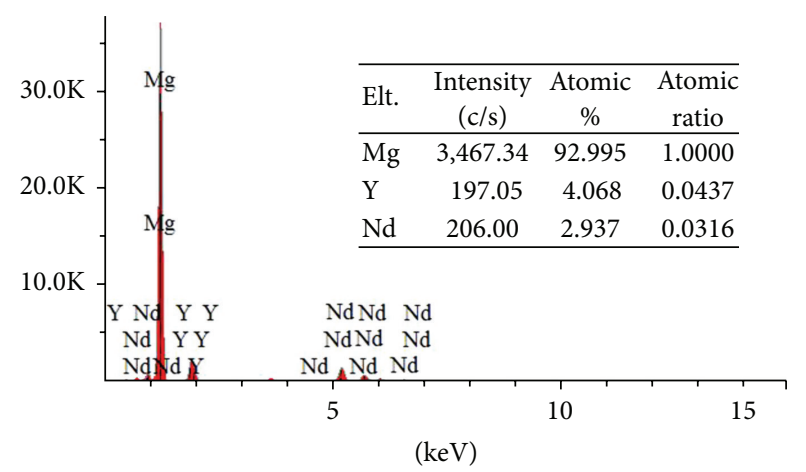

(a)

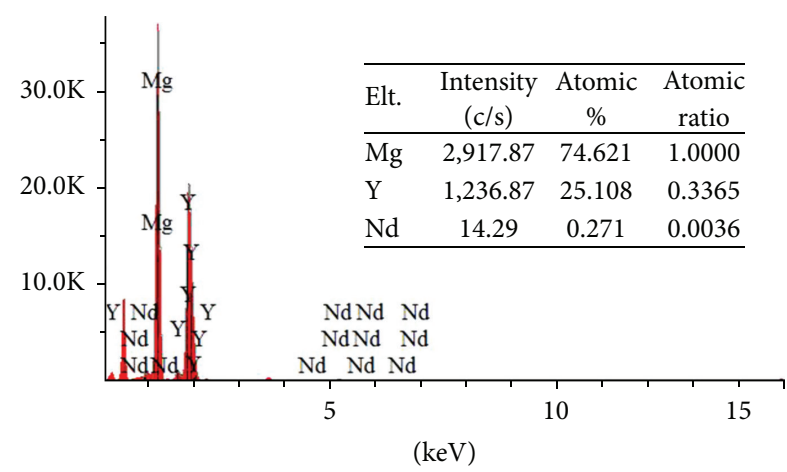

(b)

FIGURE 2: The EDS results of different precipitations in as-cast Mg-5Y-1.5Nd alloy: (a) $\mathrm{Mg}_{12}(\mathrm{Y}, \mathrm{Nd})$ and (b) $\mathrm{Mg}_{3}(\mathrm{Y}, \mathrm{Nd}$ ).

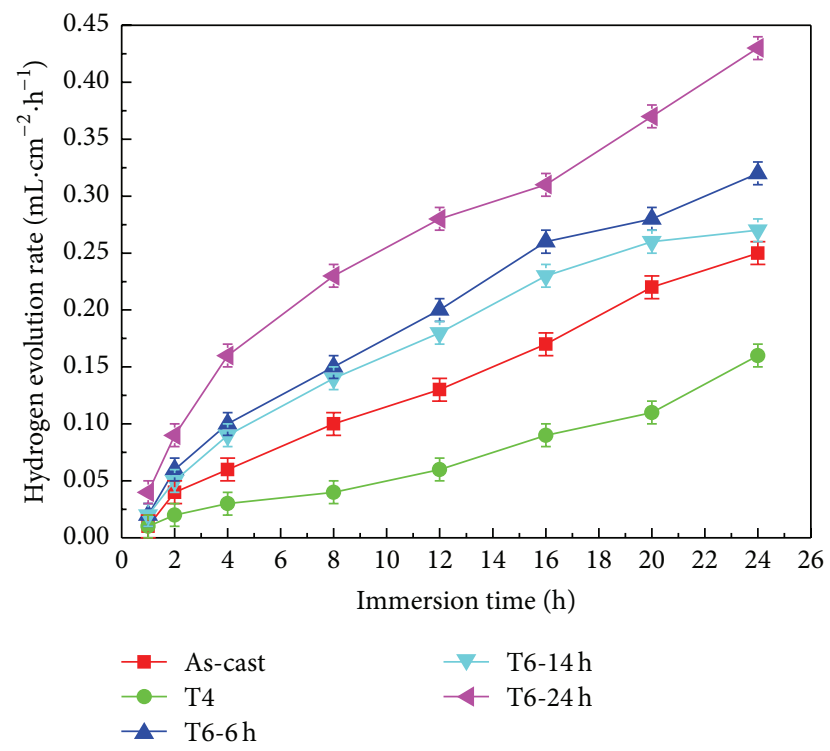

FIGURE 3: The average hydrogen evolution rates of samples measured in $3.5 \% \mathrm{NaCl}$.

the highest corrosion rate of $1.3331 \mathrm{mg} \cdot \mathrm{cm}^{-2} \cdot \mathrm{h}^{-1}$, whereas the T4 sample had the lowest at $0.3259 \mathrm{mg} \cdot \mathrm{cm}^{-2} \cdot \mathrm{h}^{-1}$. The weight loss rates could be arranged as T6-24 h>T6-6 h>T6-14 h>ascast $>\mathrm{T} 4$. When T6 sample was aged at $225^{\circ} \mathrm{C}$ for $6 \mathrm{~h}$, bulky precipitated phases formed in the $\alpha$-Mg matrix and along the grain boundary, resulting in the fact that the corrosion rate had a large increase. When the aging times increased from $6 \mathrm{~h}$ to $14 \mathrm{~h}$, the precipitated phases were distributed uniformly to form a corrosion barrier, so the weight loss rate decreased to some extent. The amount of precipitated phases became the largest after the T6-24 h heat treatment, which acted as the cathode of electrochemical reactions. As a result, acceleration of the corrosion was more effective than the corrosion barrier, so the T6-24 h samples corroded most seriously.

3.3. Corrosion Products and Surface Morphologies. The corrosion products formed on the surface of samples were characterized by XRD in Figure 5. It could be demonstrated that $\mathrm{Mg}, \mathrm{Mg}(\mathrm{OH})_{2}, \mathrm{Y}(\mathrm{OH})_{3}$, and $\mathrm{Nd}(\mathrm{OH})_{3}$ were the main

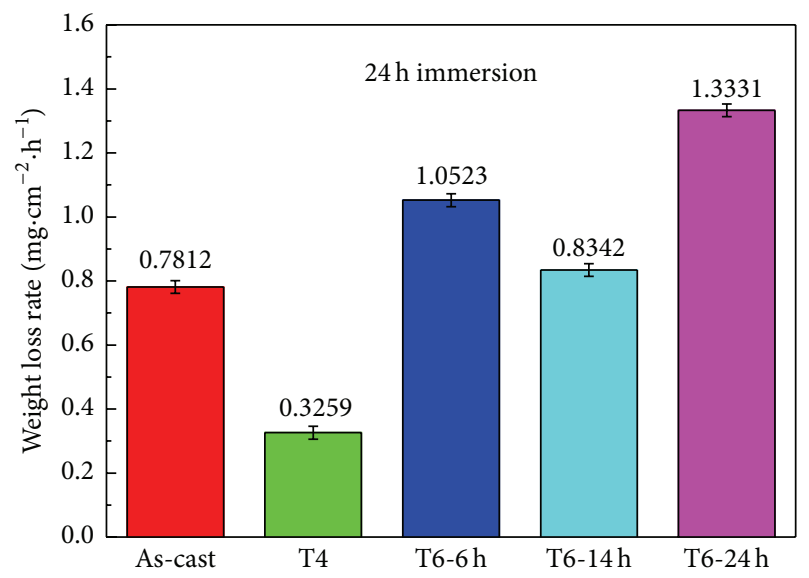

FIGURE 4: The weight loss rates of samples after immersion in $3.5 \%$ $\mathrm{NaCl}$ for 24 hours.

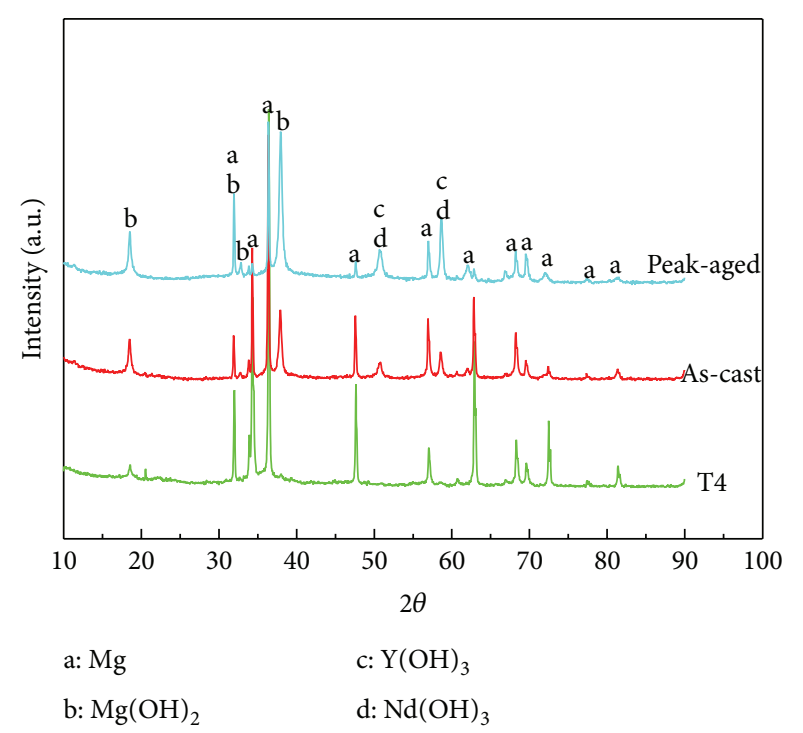

FIGURE 5: The XRD of corrosion products formed on different samples.

components analyzed by Jade 5.0 software. However, the characteristic peaks of $\mathrm{Mg}$ in the corrosion products on 


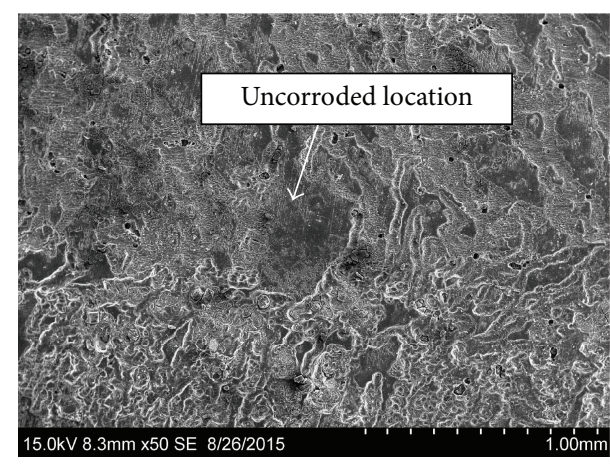

(a)

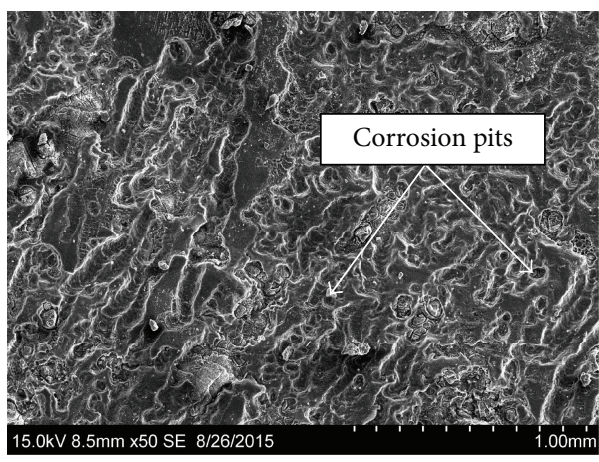

(c)

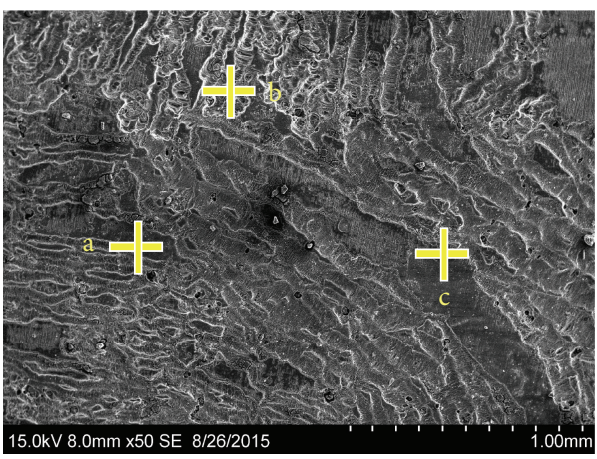

(e)

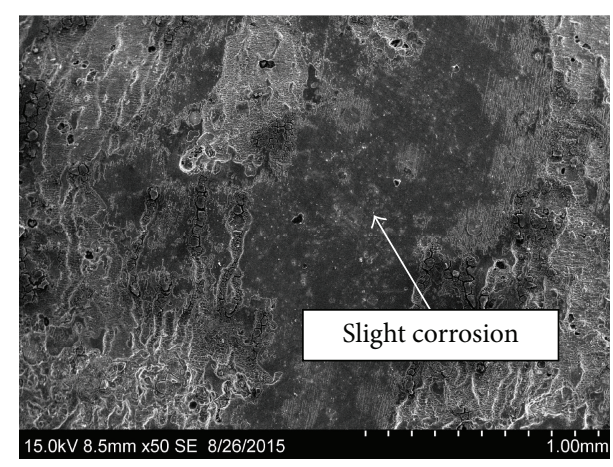

(b)

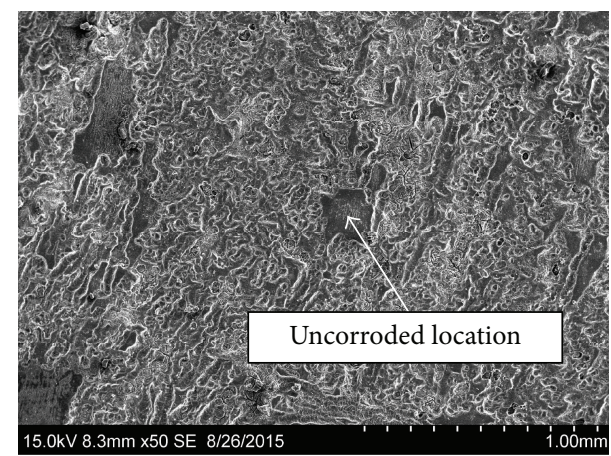

(d)

\begin{tabular}{lccc}
\hline Locations & $\mathrm{Mg}$ (at.\%) & $\mathrm{Y}($ at.\%) & $\mathrm{Nd}$ (at.\%) \\
\hline $\mathrm{a}$ & 99.377 & 0.533 & 0.090 \\
$\mathrm{~b}$ & 74.051 & 25.745 & 0.204 \\
$\mathrm{c}$ & 91.936 & 5.226 & 2.838 \\
\hline
\end{tabular}

(f)

FIGURE 6: The surface morphologies without corrosion products of different samples: (a) as-cast, (b) T4, (c) T6-6 h, (d) T6-14 h, (e) T6-24 h, and (f) EDS results.

the T4 sample were higher than these of other samples, whereas the characteristic peaks of $\mathrm{Mg}(\mathrm{OH})_{2}, \mathrm{Y}(\mathrm{OH})_{3}$, and $\mathrm{Nd}(\mathrm{OH})_{3}$ were just the reverse. More interestingly, the characteristic peaks of $\mathrm{Y}(\mathrm{OH})_{3}$ and $\mathrm{Nd}(\mathrm{OH})_{3}$ in the corrosion products were found in the as-cast and peak-aged samples, which is not consistent with the literature $[29,30]$. Normally, the amounts of $\mathrm{Y}(\mathrm{OH})_{3}$ and $\mathrm{Nd}(\mathrm{OH})_{3}$ in the corrosion products were less to detect. The phenomenon indicated that the as-cast and peak-aged samples had corroded seriously. Thus, characteristic peaks of $\mathrm{Y}(\mathrm{OH})_{3}$ and $\mathrm{Nd}(\mathrm{OH})_{3}$ appeared in the corrosion products.

After immersion test, the surface morphologies without corrosion products were shown in Figure 6. The corrosion attack of as-cast sample occurred horizontally in Figure 6(a), while the partial $\alpha-M g$ matrix and precipitated phases remained intact. The large uncorroded locations were irregularly distributed over the T4 samples, which indicated that the slightest damage occurred on the surface of alloys. Serious corrosion had occurred between the matrix and precipitates for T6-6 h sample, resulting in a large number of corrosion pits. However, corrosion on the surface morphologies of the peak-aged alloy (T6-14 h) showed a decreasing tendency. With the extension of aging time, the corrosion of overaged sample was aggravated gradually; even some corrosion areas were almost completely corroded. The most serious corrosion occurred in Figure 6(e); only a small quantity of precipitated phases existed.

3.4.Electrochemical Characterizations. Figure 7 shows the electrochemical characterizations, corrosion potential $\left(E_{\mathrm{corr}}\right)$, 

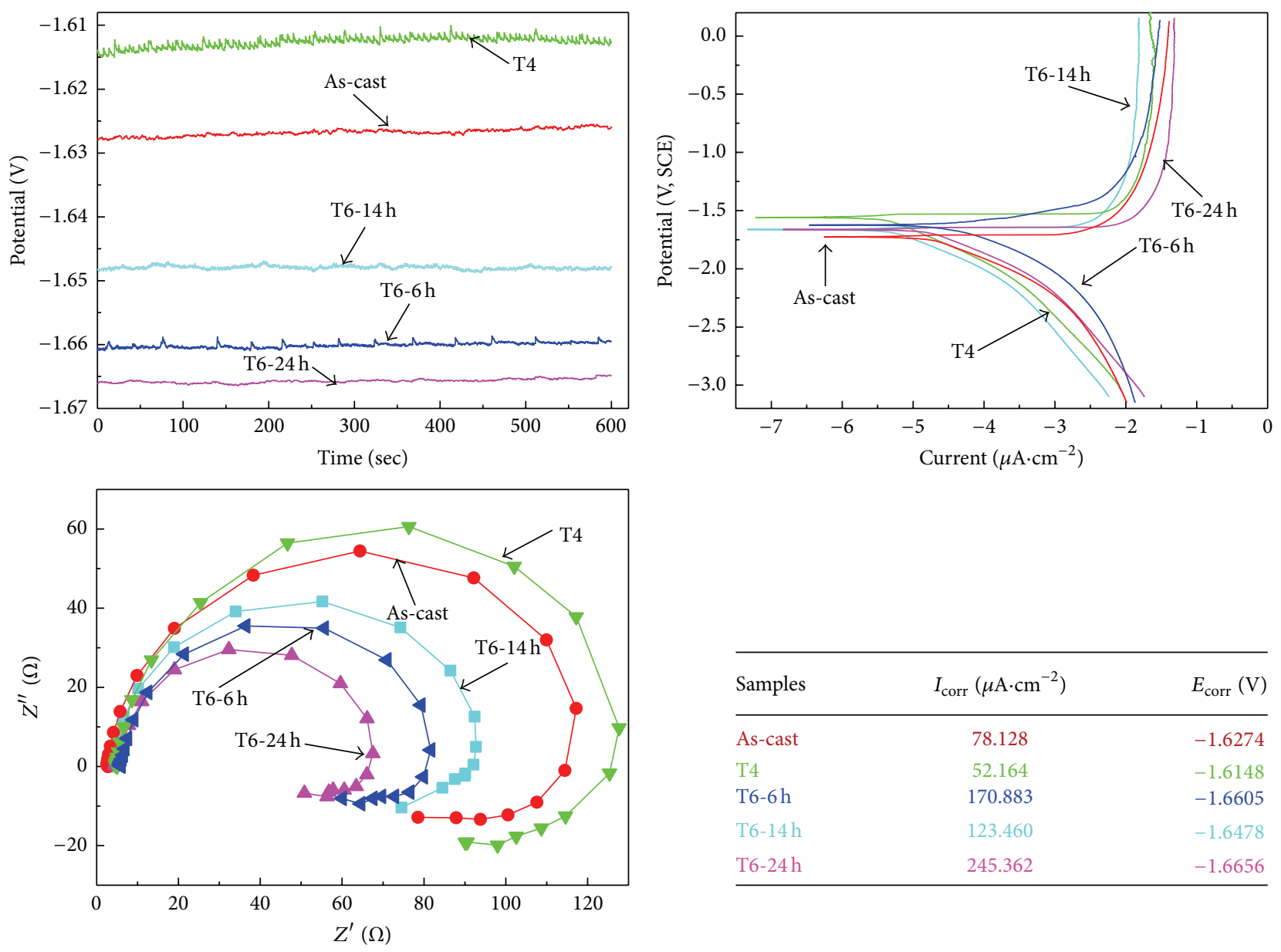

\begin{tabular}{lcc}
\hline Samples & $I_{\text {corr }}\left(\mu \mathrm{A} \cdot \mathrm{cm}^{-2}\right)$ & $E_{\text {corr }}(\mathrm{V})$ \\
\hline As-cast & 78.128 & -1.6274 \\
T4 & 52.164 & -1.6148 \\
T6-6h & 170.883 & -1.6605 \\
T6-14h & 123.460 & -1.6478 \\
T6-24h & 245.362 & -1.6656 \\
\hline
\end{tabular}

Figure 7: The electrochemical characterizations, corrosion potential $\left(E_{\text {corr }}\right)$, and corrosion current $\left(I_{\text {corr }}\right)$ of Mg-5Y-1.5Nd alloy measured in $3.5 \% \mathrm{NaCl}$ solution.

and corrosion current $\left(I_{\text {corr }}\right)$ of different samples measured in $3.5 \% \mathrm{NaCl}$ solution. The open circuit potential was comparatively stable before measurement. All the samples achieved a relatively stable value soon and equilibrium had been established. A corrosion product film formed on the surface of the samples, and no clear localized corrosion occurred. It was interesting to find that the T4 sample had a more positive OCP $(-1.6148 \mathrm{~V})$ than other samples, which meant lower driving on self-corrosion than as-cast and T6 samples. The OCP results implied that the electrochemical activity order could be arranged as T6-24 h>T6-6 h>T6-14 h>as-cast $>$ T4 .

The potentiodynamic polarization curves of $\mathrm{Mg}-5 \mathrm{Y}-$ $1.5 \mathrm{Nd}$ alloy of different samples had been investigated. The cathodic Tafel slopes were similar for samples in different conditions, which indicated that hydrogen evolution reaction occurred [31, 32]. In contrast to the anodic branch, the cathodic branch exhibited linear Tafel behavior for potentials more negative than a critical potential. It is well known that the current associated with reduction of oxygen can be neglected and the cathodic process within the Tafel region was mainly hydrogen evolution in astatic solution without stirring; the anodic polarization curves of magnesium alloys have a complicated nature for the reason of simultaneous combination of both anodic dissolution and hydrogen evolution at anodic polarized area; thus, the Tafel extrapolation for calculating corrosion current density could be carried out via tangent line of cathodic branch. The values of corrosion current density of Mg-5Y-1.5Nd alloys were shown in Figure 7. The value of $I_{\text {corr }}$ for T6-24h sample was the highest of $245.362 \mu \mathrm{A} \cdot \mathrm{cm}^{-2}$, because $\mathrm{Mg}_{3}(\mathrm{Y}, \mathrm{Nd})$ and $\mathrm{Mg}_{12}(\mathrm{Y}, \mathrm{Nd})$ phases along the grain boundaries acted as cathode of the electrochemical reaction to accelerate the corrosion process. $I_{\text {corr }}$ of T6-14 h sample became lower than T6-6 h, because the continuous distribution of $\mathrm{Mg}_{12}(\mathrm{Y}, \mathrm{Nd})$ phases formed a corrosion barrier to protect the $\alpha$-matrix. These results were consistent with the weight loss rate and surface corrosion morphologies mentioned above. The electrochemical impedance spectroscopy exhibited different characterizations of electrochemical corrosion reaction. The semicircle of EIS of T4 sample was the largest, which illustrated that hydrogen evolution reaction was most difficult on the $\alpha-\mathrm{Mg}$ matrix. This phenomenon demonstrated that T4 sample with a single phase had the lowest microgalvanic reaction. 


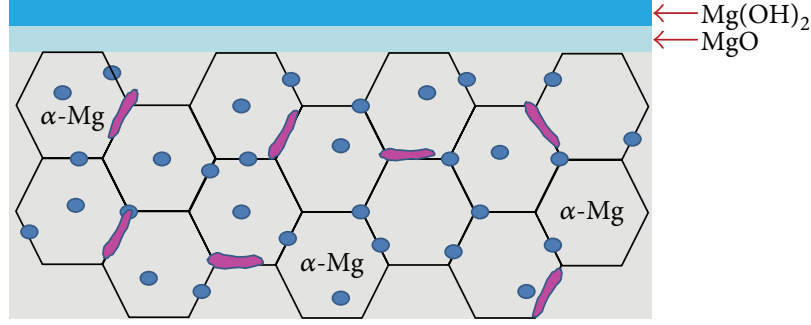

0 - $\mathrm{Mg} \quad-\mathrm{Mg}_{12}(\mathrm{Y}, \mathrm{Nd})$

- $\mathrm{Mg}_{3}(\mathrm{Y}, \mathrm{Nd})$

(a)

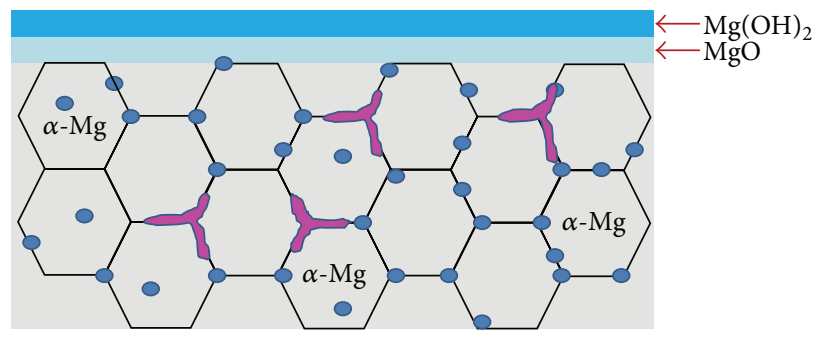

$\square-\mathrm{Mg}$

- $\mathrm{Mg}_{3}(\mathrm{Y}, \mathrm{Nd})$
- $\mathrm{Mg}_{12}(\mathrm{Y}, \mathrm{Nd})$

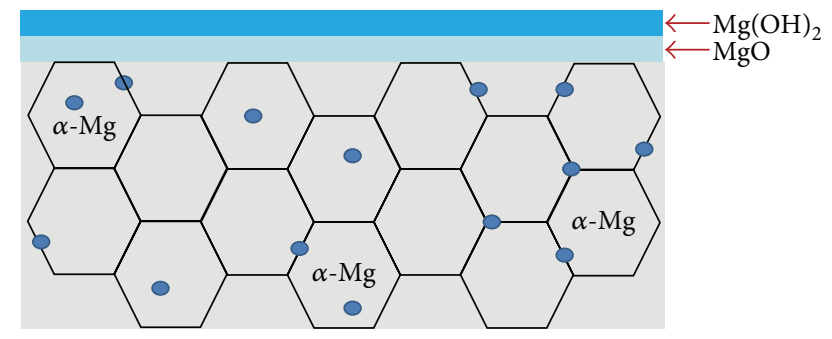

$0-\mathrm{Mg} \quad-\mathrm{Mg}_{12}(\mathrm{Y}, \mathrm{Nd})$

- $\mathrm{Mg}_{3}(\mathrm{Y}, \mathrm{Nd})$

(b)

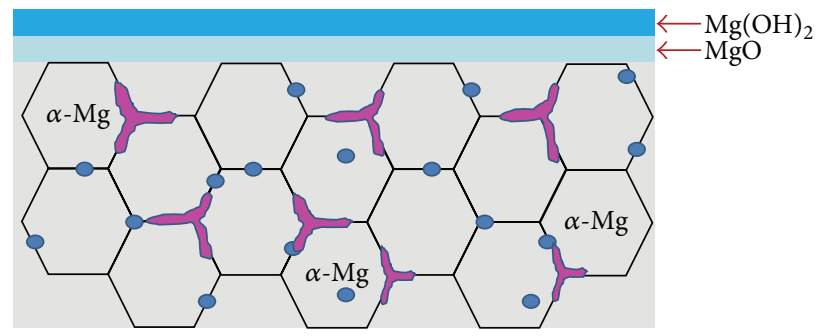

$\square \alpha-\mathrm{Mg} \quad-\mathrm{Mg}_{12}(\mathrm{Y}, \mathrm{Nd})$

- $\mathrm{Mg}_{3}(\mathrm{Y}, \mathrm{Nd})$

(d)

(c)

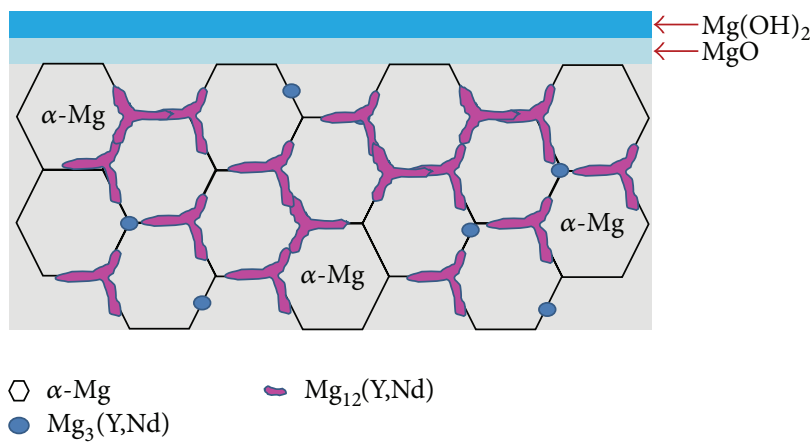

(e)

Figure 8: The schematic diagram of microstructure related to the corrosion mechanism: (a) as-cast, (b) T4, (c) T6-6 h, (d) T6-14 h, and (e) T6-24h.

The corrosion of aged samples is consistent with the increased microgalvanic corrosion acceleration of $\alpha$-phase that had an intrinsic corrosion rate. Increased aging time increased the amount of the precipitated phases. The increasing current corrosion density in the sequence aged samples can be attributed to a combination of these two effects: (i) Y and $\mathrm{Nd}$ elements precipitated from the grain, resulting in the fact that the potential of the matrix became lower, and (ii) increasing microgalvanic corrosion between the precipitated phases and matrix directly increased the corrosion rate. However, the peak-aged sample showed a decreasing trend compared with the early-aged sample, and then the overaged sample continued to increase compared with the peak-aged sample. This phenomenon indicated that the low corrosion rate of peak-aged sample was attributed to a continuous network of the precipitated phases, which would be expected to act as a barrier to corrosion propagation.

3.5. Corrosion Mechanism. The schematic diagram of microstructure related to the corrosion mechanism was shown in Figure 8. Actually, there was a difference at the volume fraction and distribution of $\mathrm{Mg}_{3}(\mathrm{Y}, \mathrm{Nd})$ and $\mathrm{Mg}_{12}(\mathrm{Y}, \mathrm{Nd})$ phases in the Mg-5Y-1.5Nd alloy after heat treatment. In this study, the corrosion rates of different samples were mainly determined by the amount and distribution of the precipitations according to the classical theory of Song et al. $[33,34]$. The phases played dual roles that depended on the amount and distribution. The presence of the phase in the alloys could deteriorate the corrosion performance as it could act as an effective galvanic cathode. Otherwise, a fine and 
homogeneous phase appeared to be a better anticorrosion barrier.

\section{Conclusion}

(1) Mg-5Y-1.5Nd alloys under different conditions were investigated to reveal the effect of heat treatment on the electrochemical corrosion behaviors. The microstructure of different samples mainly consisted of $\alpha-\mathrm{Mg}$ matrix and $\mathrm{Mg}_{12}(\mathrm{Y}, \mathrm{Nd})$ and $\mathrm{Mg}_{3}(\mathrm{Y}, \mathrm{Nd})$ phases. The precipitated phases almost dissolved into the $\alpha$-Mg matrix. The amount and volume fraction of $\mathrm{Mg}_{12}(\mathrm{Y}, \mathrm{Nd})$ and $\mathrm{Mg}_{3}(\mathrm{Y}, \mathrm{Nd})$ phases increased with the prolongation of aging times.

(2) The T6-24h sample showed the weight loss rate of $1.3331 \mathrm{mg} \cdot \mathrm{cm}^{-2} \cdot \mathrm{h}^{-1}$, whereas the T4 sample had the lowest rate at $0.3259 \mathrm{mg} \cdot \mathrm{cm}^{-2} \cdot \mathrm{h}^{-1}$. The electrochemical corrosion activity of different samples could be arranged as T6-24 h>T6-6h>T6-14 h>as-cast $>$ T4. Precipitated phases formed along the grain boundary after the aging treatment, resulting in the fact that the corrosion reaction increased rapidly. However, precipitated phases of peak-aged sample were distributed uniformly to form a corrosion barrier.

(3) The microstructural influence of corrosion can be understood from the interaction of the following three factors: (i) the surface film formed on the surface of the $\alpha$ $\mathrm{Mg}$ can be more or less effective in hindering corrosion and more or less effective in controlling the form of corrosion as uniform corrosion or localized corrosion, (ii) the precipitated phases $\mathrm{Mg}_{12}(\mathrm{Y}, \mathrm{Nd})$ and $\mathrm{Mg}_{3}(\mathrm{Y}, \mathrm{Nd})$ can cause microgalvanic acceleration of corrosion of the matrix $\alpha-\mathrm{Mg}$, and (iii) the precipitated phases can act as a corrosion barrier and hinder the corrosion propagation in matrix.

(4) The electrochemical results confirmed that the microstructure and precipitated phases of $\mathrm{Mg}-5 \mathrm{Y}-1.5 \mathrm{Nd}$ alloys played an important role, which indicated that the corrosion resistance of $\mathrm{Mg}-\mathrm{Y}-\mathrm{Nd}$ alloy can be modified via heat treatment. This research is expected to provide a guiding insight into developing the Mg-Y-Nd based alloys.

\section{Competing Interests}

The authors declare that they have no competing interests.

\section{Acknowledgments}

The authors gratefully acknowledge the National Natural Science Foundation of China (Grant no. 51501181) and China Postdoctoral Science Foundation (Grant no. 2015M582155) for providing support for this work.

\section{References}

[1] L. L. Rokhlin, Magnesium Alloys Containing Rare Earth Metals, Taylor and Francis, London, UK, 2003.

[2] M. Liu, P. Schmutz, P. J. Uggowitzer, G. Song, and A. Atrens, "The influence of yttrium (Y) on the corrosion of Mg-Y binary alloys," Corrosion Science, vol. 52, no. 11, pp. 3687-3701, 2010.
[3] J. Chang, X. Guo, S. He et al., "Investigation of the corrosion for Mg-xGd-3Y-0.4Zr ( $\mathrm{x}=6,8,10,12 \mathrm{wt} \%)$ alloys in a peak-aged condition," Corrosion Science, vol. 50, no. 1, pp. 166-177, 2008.

[4] G. Williams, K. Gusieva, and N. Birbilis, "Localized corrosion of binary $\mathrm{Mg}-\mathrm{Nd}$ alloys in chloride-containing electrolyte using a scanning vibrating electrode technique," Corrosion, vol. 68, no. 6, pp. 489-498, 2012.

[5] X. Zhang, Z. Wang, G. Yuan, and Y. Xue, "Improvement of mechanical properties and corrosion resistance of biodegradable $\mathrm{Mg}-\mathrm{Nd}-\mathrm{Zn}-\mathrm{Zr}$ alloys by double extrusion," Materials Science and Engineering B, vol. 177, no. 13, pp. 1113-1119, 2012.

[6] N.-C. Quach, P. J. Uggowitzer, and P. Schmutz, "Corrosion behaviour of an Mg-Y-RE alloy used in biomedical applications studied by electrochemical techniques," Comptes Rendus Chimie, vol. 11, no. 9, pp. 1043-1054, 2008.

[7] Z. C. Li, H. Zhang, L. Liu, and Y. B. Xu, "Growth and morphology of $\beta$ phase in an Mg-Y-Nd alloy," Materials Letters, vol. 58, no. 24, pp. 3021-3024, 2004.

[8] Q. Jiang, K. Zhang, X. Li et al., "The corrosion behaviors of Mg-7Gd-5Y-1Nd-0.5Zr alloy under $\left(\mathrm{NH}_{4}\right)_{2} \mathrm{SO}_{4}, \mathrm{NaCl}$ and $\mathrm{Ca}\left(\mathrm{NO}_{3}\right)_{2}$ salts spray condition," Journal of Magnesium and Alloys, vol. 1, no. 3, pp. 230-234, 2013.

[9] T. Li, Z. W. Du, K. Zhang et al., "Characterisation of precipitates in a Mg-7Gd-5Y-1Nd-0.5Zr alloy aged to peak-ageing plateau," Journal of Alloys and Compounds, vol. 574, pp. 174-180, 2013.

[10] R. Xin, B. Song, K. Zeng, G. Huang, and Q. Liu, "Effect of aging precipitation on mechanical anisotropy of an extruded Mg-YNd alloy," Materials and Design, vol. 34, pp. 384-388, 2012.

[11] R. Xin, L. Li, K. Zeng, B. Song, and Q. Liu, "Structural examination of aging precipitation in a $\mathrm{Mg}-\mathrm{Y}-\mathrm{Nd}$ alloy at different temperatures," Materials Characterization, vol. 62, no. 5, pp. 535-539, 2011.

[12] S. M. Zhu and J. F. Nie, "Serrated flow and tensile properties of a Mg-Y-Nd alloy," Scripta Materialia, vol. 50, no. 1, pp. 51-55, 2004.

[13] J.-F. Nie, "Precipitation and hardening in magnesium alloys," Metallurgical and Materials Transactions A, vol. 43, no. 11, pp. 3891-3939, 2012.

[14] A. J. Davenport, C. Padovani, B. J. Connolly et al., "Synchrotron $\mathrm{X}$-ray microtomography study of the role of $\mathrm{Y}$ in corrosion of magnesium alloy WE43," Electrochemical and Solid-State Letters, vol. 10, no. 2, pp. C5-C8, 2007.

[15] X. Zhang, Z. Wang, G. Yuan, and Y. Xue, "Improvement of mechanical properties and corrosion resistance of biodegradable Mg-Nd-Zn-Zr alloys by double extrusion," Materials Science and Engineering: B, vol. 177, no. 13, pp. 1113-1119, 2012.

[16] G. Song, A. L. Bowles, and D. H. StJohn, "Corrosion resistance of aged die cast magnesium alloy AZ91D," Materials Science and Engineering: A, vol. 366, no. 1, pp. 74-86, 2004.

[17] M.-C. Zhao, M. Liu, G. Song, and A. Atrens, "Influence of the $\beta$-phase morphology on the corrosion of the Mg alloy AZ91," Corrosion Science, vol. 50, no. 7, pp. 1939-1953, 2008.

[18] G. Song and A. Atrens, "Understanding magnesium corrosion-A framework for improved alloy performance," Advanced Engineering Materials, vol. 5, no. 12, pp. 837-858, 2003.

[19] A. Atrens, G. L. Song, F. Cao, Z. Shi, and P. K. Bowen, "Advances in Mg corrosion and research suggestions," Journal of Magnesium and Alloys, vol. 1, no. 3, pp. 177-200, 2013.

[20] Z.-C. Wang, L. Yu, F. Jia, and G.-L. Song, "Effect of additives and heat treatment on the formation and performance of 
electroless nickel-boron plating on AZ91D Mg alloy," Journal of the Electrochemical Society, vol. 159, no. 7, pp. D406-D412, 2012.

[21] Y. Lu, A. R. Bradshaw, Y. L. Chiu et al., "The role of $\beta_{1}^{\prime}$ precipitates in the bio-corrosion performance of $\mathrm{Mg}-3 \mathrm{Zn}$ in simulated body fluid," Journal of Alloys and Compounds, vol. 614, pp. 345-352, 2014.

[22] G. Ben-Hamu, D. Eliezer, K. S. Shin, and S. Cohen, "The relation between microstructure and corrosion behavior of Mg-Y-RE$\mathrm{Zr}$ alloys," Journal of Alloys and Compounds, vol. 431, no. 1-2, pp. 269-276, 2007.

[23] M. Kiryuu, H. Okumura, S. Kamado et al., "Corrosion resistance of heat resistant magnesium alloys containing heavy rare earth elements," Journal of Japan Institute of Light Metals, vol. 46, pp. 39-44, 1996.

[24] L. L. Rokhlin, T. V. Dobatkina, I. E. Tarytina, V. N. Timofeev, and E. E. Balakhchi, "Peculiarities of the phase relations in Mg-rich alloys of the Mg-Nd-Y system," Journal of Alloys and Compounds, vol. 367, no. 1-2, pp. 17-19, 2004.

[25] Q. Jiang, M. Ma, K. Zhang et al., "Corrosion behavior of extrusion, under-aged, peaked-aged and over-aged WE93 alloys in $\mathrm{NaHSO}_{3}$ solutions," Journal of Rare Earths, vol. 32, no. 12, pp. 1170-1174, 2014.

[26] G.-L. Song and Z. Q. Xu, "The surface, microstructure and corrosion of magnesium alloy AZ31 sheet," Electrochimica Acta, vol. 55, no. 13, pp. 4148-4161, 2010.

[27] B. Smola and I. Stulíková, "Equilibrium and transient phases in Mg-Y-Nd ternary alloys," Journal of Alloys and Compounds, vol. 381, no. 1-2, pp. L1-L2, 2004.

[28] M. Ma, K. Zhang, X. Li, Y. Li, G. Shi, and J. Yuan, "Influence of solution and aging on the microstructures and mechanical properties of complex deformed WE93 alloy," Materials and Design, vol. 51, pp. 73-78, 2013.

[29] J.-W. Chang, X.-W. Guo, P.-H. Fu, L.-M. Peng, and W.-J. Ding, "Effect of heat treatment on corrosion and electrochemical behaviour of Mg-3Nd-0.2Zn-0.4Zr (wt.\%) alloy," Electrochimica Acta, vol. 52, no. 9, pp. 3160-3167, 2007.

[30] F. Zucchi, V. Grassi, A. Frignani, C. Monticelli, and G. Trabanelli, "Electrochemical behaviour of a magnesium alloy containing rare earth elements," Journal of Applied Electrochemistry, vol. 36, no. 2, pp. 195-204, 2006.

[31] W. Unsworth and J. F. King, Magnesium Technology, The Institute of Metals, London, UK, 1987.

[32] B. J. Wang, D. K. Xu, J. H. Dong, and W. Ke, "Effect of the crystallographic orientation and twinning on the corrosion resistance of an as-extruded Mg-3Al-1Zn (wt.\%) bar," Scripta Materialia, vol. 88, pp. 5-8, 2014.

[33] G. L. Song and A. Atrens, "Corrosion mechanisms of magnesium alloys," Advanced Engineering Materials, vol. 1, no. 1, pp. 11-33, 1999.

[34] A. Atrens, G.-L. Song, M. Liu, Z. Shi, F. Cao, and M. S. Dargusch, "Review of recent developments in the field of magnesium corrosion," Advanced Engineering Materials, vol. 17, no. 4, pp. 400-453, 2015. 

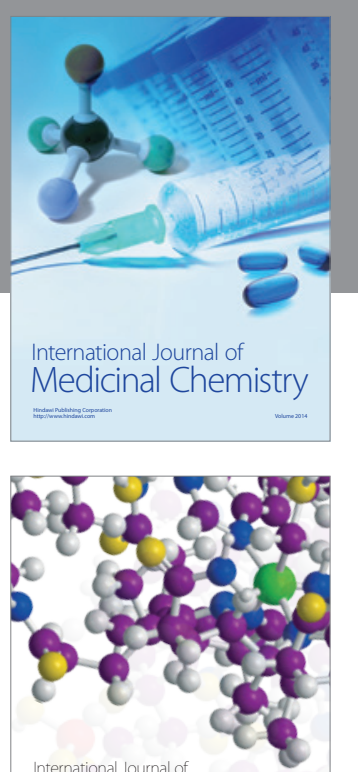

Carbohydrate Chemistry

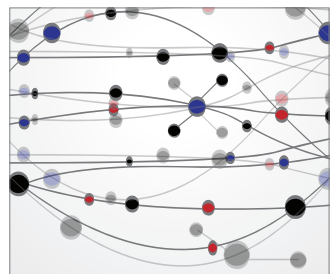

The Scientific World Journal
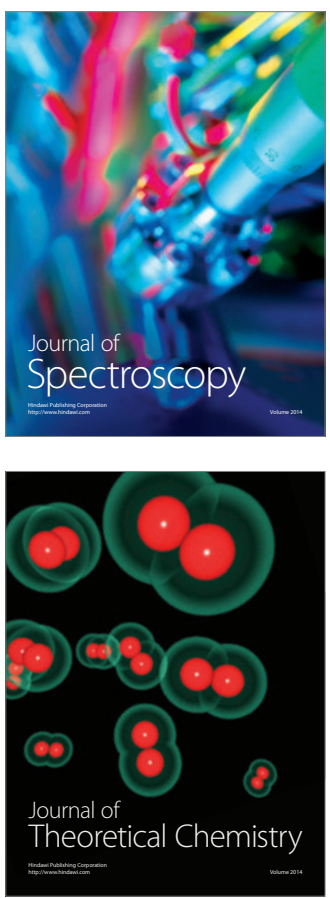
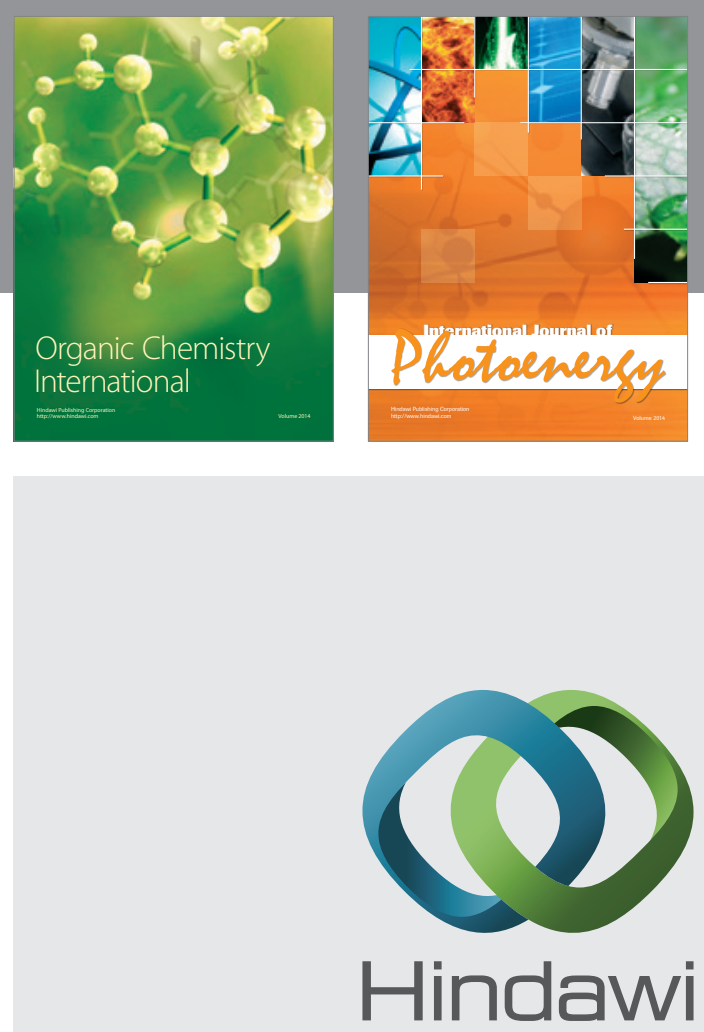

Submit your manuscripts at

http://www.hindawi.com

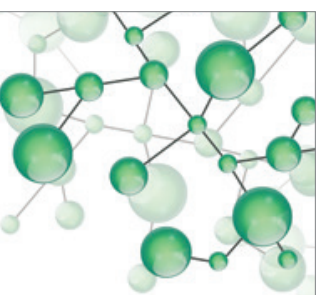

International Journal of

Inorganic Chemistry

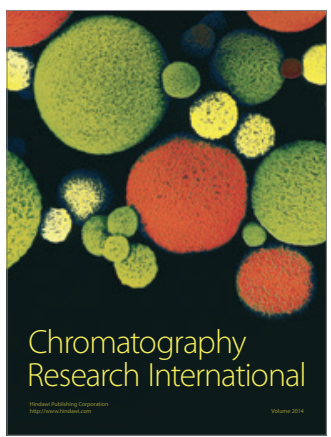

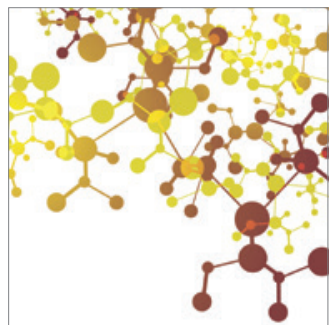

Applied Chemistry
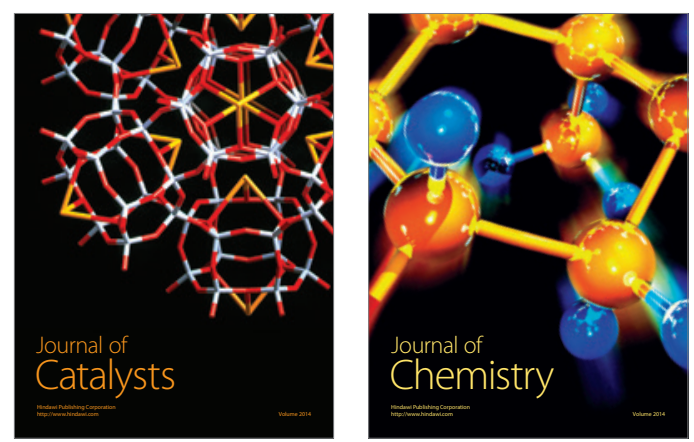
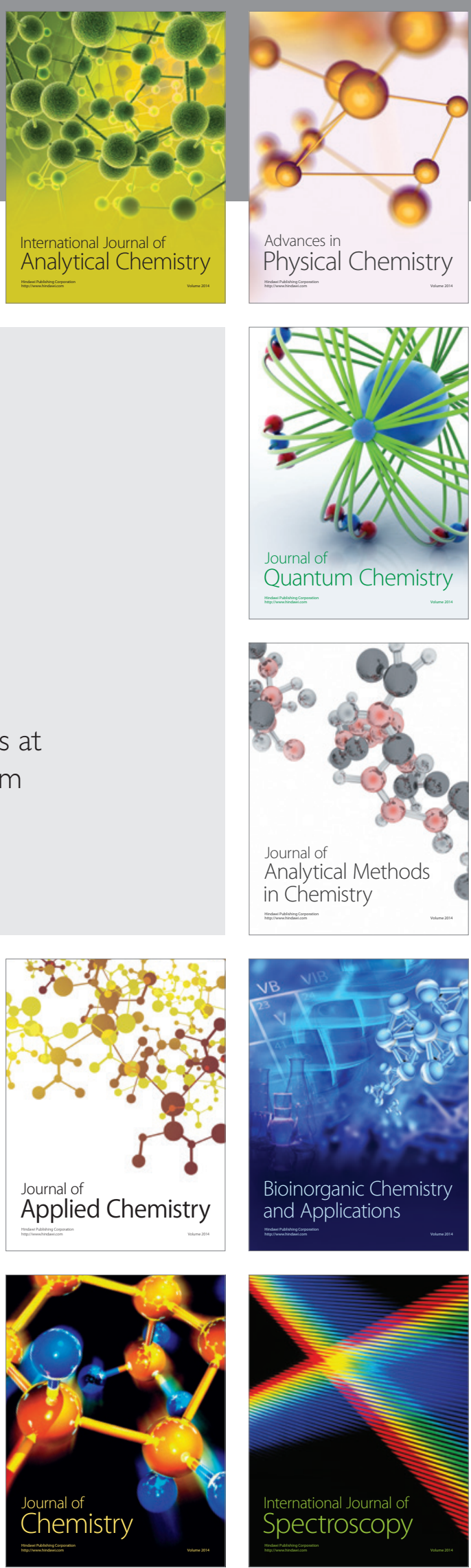